Case Study

\title{
Multi-step approach to add value to corncob: Production of biomass- degrading enzymes, lignin and fermentable sugars
}

\author{
Michele Michelin $^{\mathrm{a}, *}$, Héctor A. Ruiz ${ }^{\mathrm{b}, \mathrm{c}}$, Maria de Lourdes T.M. Polizeli ${ }^{\mathrm{d}}$, José A. Teixeira ${ }^{\mathrm{a}}$ \\ ${ }^{\text {a }}$ CEB - Centre of Biological Engineering, University of Minho, Campus Gualtar, 4710-057 Braga, Portugal \\ b Biorefinery Group, Food Research Department, Faculty of Chemistry Sciences, Autonomous University of Coahuila, 25280 Saltillo, Coahuila, Mexico \\ c Cluster of Bioalcohols, Mexican Centre for Innovation in Bioenergy (Cemie-Bio), Mexico \\ d Department of Biology, School of Philosophy, Sciences and Literature of Ribeirão Preto, University of São Paulo, Ribeirão Preto, SP 14040-901, Brazil
}

\section{A R T I C L E I N F O}

\section{Keywords:}

Autohydrolysis

Enzymes

Saccharification

Aspergillus niger

Trichoderma reesei

\begin{abstract}
A B S T R A C T
This work presents an integrated and multi-step approach for the recovery and/or application of the lignocellulosic fractions from corncob in the production of high value added compounds as xylo-oligosaccharides, enzymes, fermentable sugars, and lignin in terms of biorefinery concept. For that, liquid hot water followed by enzymatic hydrolysis were used. Liquid hot water was performed using different residence times (10-50 min) and holding temperature $\left(180-200{ }^{\circ} \mathrm{C}\right)$, corresponding to severities $\left(\log \left(R_{0}\right)\right)$ of $3.36-4.64$. The most severe conditions showed higher xylo-oligosaccharides extraction (maximum of 93\%) into the hydrolysates and higher recovery of cellulose on pretreated solids (maximum of 65\%). Subsequently, hydrolysates and solids were used in the production of xylanases and cellulases, respectively, as well as, pretreated solids were also subjected to enzymatic hydrolysis for the recovery of lignin and fermentable sugars from cellulose. Maximum glucose yield $(100 \%)$ was achieved for solids pretreated at $\log \left(R_{0}\right)$ of 4.42 and $5 \%$ solid loading.
\end{abstract}

\section{Introduction}

The harvested production of cereals in the EU-28 was around 317 million tonnes in 2015 . This represented about $12.5 \%$ of global cereal production (FAO, 2016). Common wheat and spelt, barley, grain maize and corn-cob-mix accounted for a high share (86\% in 2015) of the cereals produced in the EU-28 (EUROSTAT, 2017). These harvests generate a large amount of lignocellulosic residues that mainly consist of cellulose $(30 \%-50 \%)$, hemicellulose $(15 \%-35 \%)$ and lignin $(10 \%-20 \%)$ that are linked with each other (Michelin et al., 2015).

These lignocellulosic materials (LCM) are organized in a complex matrix that needs to be broken in order to isolate the lignocellulosic components. Biomass-degrading enzymes act on hydrolysis of the polymeric cellulose or hemicellulose into oligosaccharides and after in sugars, which can be fermented by microorganisms, or used as building blocks, for synthesis of fuel or chemicals. In general, these enzymes, i.e. cellulases and hemicellulases, consist of an enzymatic complex that works synergically to hydrolyze the different regions of cellulose and hemicellulose on lignocellulose, according to their specificity (Sweeney and $\mathrm{Xu}, 2012)$.

The enzymatic hydrolysis of cellulose has been shown to improve significantly with the removal of hemicellulose, suggesting that hemicellulose acts as a barrier to the hydrolysis of cellulose by cellulolytic enzymes (Yang et al., 2011). Thus, the pretreatment of LCM before hydrolysis is a prerequisite and it can be performed by different methods. Liquid hot water (LHW) pretreatment or autohydrolysis (hydrothermal processing) allows a high recovery of hemicelluloses as soluble saccharides, while both cellulose and lignin could be recovered in the solid phase as essentially non-degraded polymers. Furthermore, it has many technological and environmental benefits, mainly related to its non-catalyzed nature, as well as limited equipment corrosion problems, reduction of operational costs, and lower byproducts generation, such as furfural and hydroxymethylfurfural (Michelin et al., 2015; Michelin and Teixeira, 2016).

This work uses LHW pretreatment, enzymatic saccharification and fungal fermentation to convert corncob residues into valuable products in terms of biorefinery. For that, xylanases (endoxylanase and $\beta$-xylosidase) and cellulases (FP activity, $\beta$-glucosidase) were produced through the fungal fermentation using the hemicellulose hydrolysates and the solid fraction (rich in cellulose), respectively, obtained from LHW pretreatment. The use of pretreated lignocellulosic residues is an important strategy to improve the enzymatic production and to compete with commercial substrates, because of the lower production cost of the enzymes associated with these residues. Moreover, a step of

\footnotetext{
* Corresponding author.

E-mail address: mimichelin.bio@gmail.com (M. Michelin).
} 
enzymatic hydrolysis (using commercial enzymatic cocktails) was performed on the solid fraction for saccharification of cellulose and recovery of lignin that was evaluated regarding to its antioxidant potential.

\section{Materials and methods}

\subsection{Materials}

Corncob (CC) was kindly supplied by a farmer from Northern Portugal. The material was dried at $40{ }^{\circ} \mathrm{C}$ for $12 \mathrm{~h}$, and after that it was cut into small chips $(1-3 \mathrm{~cm})$, milled using a knives mill to pass through a $1.0 \mathrm{~mm}$ screen, and stored at room temperature until use. Cellic ${ }^{\oplus}$ Ctec2 (a blend of cellulases and hemicellulases) and NS 22083 (xylanases) were kindly given by Novozymes (Bagsvaerd, Denmark). Whatman ${ }^{\circledR}$ filter paper grade 1 (Whatman International Ltd, England), Beechwood xylan, $\rho$-nitrophenyl- $\beta$-D-glucopyranoside and $\rho$-nitrophenyl- $\beta$-D-xylopyranoside, 1,1-diphenyl-2-picrylhydrazyl (DPPH), trolox and butylated hydroxytoluene (BHT) were purchased from Sigma-Aldrich (St. Louis, MO, USA).

\subsection{Liquid hot water (LHW) pretreatment}

LHW pretreatment of CC was carried out in $160 \mathrm{~mL}$ stainless steel cylinder reactors $(4.0 \mathrm{~cm}$ internal diameter and $12.4 \mathrm{~cm}$ internal height), with a working volume of $50 \mathrm{~mL}$ ). Milled CC samples of $1.0 \mathrm{~mm}$ and water were added into the closed and pressurized vessel at $10 \%(\mathrm{w} / \mathrm{v})$ solids loading. The reactor was submerged in an oil bath with an open heating circulator (Julabo Labortechnik GmbH, Seelbath, Germany) with PID temperature control at 180,190 and $200{ }^{\circ} \mathrm{C}$ and maintained for a certain residence time (10, 30 and $50 \mathrm{~min})$. After that, the reactor was immediately cooled in an ice bath to quench the reaction. The pretreated slurry was vacuum filtered using Whatman ${ }^{\circledR} \mathrm{N}^{\circ} 1$ filter paper to separate the liquid (hydrolysates) and solid fractions. The $\mathrm{pH}$ value of the hydrolysates was measured using a digital $\mathrm{pH}$ meter and after that it was stored frozen. Solids were washed with distilled water, and after that dried at $40{ }^{\circ} \mathrm{C}$.

Intensity of pretreatments was measured in terms of severity index $\left(\log \left(R_{0}\right)\right)$ calculated according to Eq. (1):

$\log \left(R_{0}\right)=\log \left[\operatorname{texp}\left(\frac{T-100}{14.75}\right)\right]$

where $t$ is the residence time ( $\mathrm{min}), T$ is the holding temperature $\left({ }^{\circ} \mathrm{C}\right)$, and 14.75 an empirical parameter related to activation energy and temperature.

\subsection{Compositional biomass analysis}

The chemical composition of CC (untreated and pretreated) was determined according to the standard Laboratory Analytical Procedures (LAPs) for biomass analysis provided by the US National Renewable Energy Laboratory (NREL) (Sluiter et al., 2008). Analyzed components were glucan, xylan, arabinan, acetyl groups, Klason lignin, and ashes. The hydrolysates of the pretreated CC were analyzed for monomeric sugars, acetic acid, oligomeric sugars, acetyl groups and degradation products (5-hydroxymethyl-2-furaldehyde (HMF) and furfural). The oligomeric sugars were calculated after a post-hydrolysis with $4 \%$ sulfuric acid at $121{ }^{\circ} \mathrm{C}$, during $60 \mathrm{~min}$. The increase in the concentrations of monosaccharides (glucose, xylose and arabinose) and acetic acid caused by post-hydrolysis was considered a measure of the concentrations of oligomers and acetyl groups bound to oligosaccharides. These components were analyzed by HPLC as described below. All measurements were made in duplicate.

The extraction yield of xylo-oligosaccharides ( $\mathrm{Y}_{\mathrm{xOS}}$ ) from feedstock xylan (gXOS/100 g xylan) was calculated according to Eq. (2):
Yield $_{X O S}=\operatorname{XOS} \frac{V}{X n_{F S}} 100$

where $X O S$ is the concentrations of xylo-oligosaccharides $(\mathrm{g} / \mathrm{L})$ on hydrolysates, $V$ is the volume of LHW assay $(\mathrm{mL})$ and $X n_{F S}$ is the percentage of xylan in feedstock material.

\subsection{HPLC analysis}

HPLC analysis of hydrolyzed samples was performed using a Metacarb $87 \mathrm{H}$ carbohydrate analysis column $(300 \times 7.8 \mathrm{~mm}$, Varian, USA) at $60{ }^{\circ} \mathrm{C}$. Sugars and acetic acid were analyzed with a refractive index (RI) detector and furfural and hydroxymethylfurfural (HMF) contents with a UV detector, both in a Jasco chromatograph. The mobile phase was $0.005 \mathrm{M} \mathrm{H}_{2} \mathrm{SO}_{4}$ in ultrapure water filtered through $0.45 \mu \mathrm{m}$ nylon filter (Millipore) and degassed. The flow rate was $0.7 \mathrm{~mL} / \mathrm{min}$.

\subsection{Microorganisms}

The microorganisms used in this work were the fungal strains Trichoderma reesei MUM 97.53 and Aspergillus niger van Tieghem. The first one was provided by MUM (Micoteca da Universidade do Minho, Portugal); and the second one obtained from Department of Biology from FFCLRP/USP (Brazil). Stock cultures were propagated on PDA medium slants (Difco Laboratories, Becton, Dickinson and Co., Sparks, MD, USA), at $30^{\circ} \mathrm{C}$ for 1 week, and stored at $4{ }^{\circ} \mathrm{C}$.

\subsection{Cultivation conditions}

Conidia from 7 day-old cultures from Trichoderma reesei MUM 97.53 and Aspergillus niger van Tieghem, with $1 \times 10^{9}$ spores per mL, were inoculated into $100 \mathrm{~mL}$ Erlenmeyer flasks containing $20 \mathrm{~mL}$ of the liquid medium described by Mandels \& Weber (1969), pH 6.0. Pretreated solids $(1 \%, \mathrm{w} / \mathrm{v})$ or hydrolysates $(100 \%, \mathrm{v} / \mathrm{v})$ were used as carbon source. Untreated CC, xylan and avicel were used as control. The cultures were incubated at $30{ }^{\circ} \mathrm{C}, 100 \mathrm{rpm}$, for 6 days. After fermentations, the mycelia and residues were removed from fermentation media by vacuum filtration using Whatman ${ }^{\circledR} \mathrm{N}^{\circ} 1$ filter paper. The filtrates were used as sources of crude extracellular cellulase or xylanase enzymes.

\subsection{Enzyme activities}

All enzymatic assays were performed using the procedure recommended by the International Union of Pure and Applied Chemistry (IUPAC). Cellulase activity was determined at $50{ }^{\circ} \mathrm{C}$ for $60 \mathrm{~min}$, according to Ghose (1987), using filter paper Whatman $\mathrm{N}^{\circ} 1$ as substrate and expressed as Filter Paper Unit per $\mathrm{mL}$ (FPU/mL). Xylanase activity was determined at $60^{\circ} \mathrm{C}$ for $20 \mathrm{~min}$, using birchwood xylan as substrate and expressed as International Unit per $\mathrm{mL}(\mathrm{IU} / \mathrm{mL})$. Release of reducing sugars from both polysaccharides was analyzed by DNS (Miller, 1959), using glucose or xylose, respectively, as standard.

$\beta$-Glucosidase activity was determined at $50{ }^{\circ} \mathrm{C}$ for $10 \mathrm{~min}$ by monitoring the hydrolysis of $p$-nitrophenol- $\beta$-D-glucopyranoside (PNPglu), and $\beta$-xylosidase activity was determined at $70{ }^{\circ} \mathrm{C}$ for $15 \mathrm{~min}$ through the hydrolysis of $p$-nitrophenol- $\beta$-D-xyloopyranoside (PNP-xyl). The released $\rho$-nitrophenolate was estimated with $1 \mathrm{M}$ sodium carbonate, using $\rho$-nitrophenol as standard and expressed as International Unit (IU) per mL. All substrates were suspended in $50 \mathrm{mM}$ sodium citrate buffer, $\mathrm{pH} 4.8$.

Cellic ${ }^{\circledR}$ Ctec 2 presented $160 \mathrm{FPU} / \mathrm{mL}$ of cellulase and $2300 \mathrm{IU} / \mathrm{mL}$ of $\beta$-glucosidase; and the NS 22083 contained $2800 \mathrm{IU} / \mathrm{mL}$ of xylanase and $135 \mathrm{IU} / \mathrm{mL}$ of $\beta$-xylosidase, respectively. 


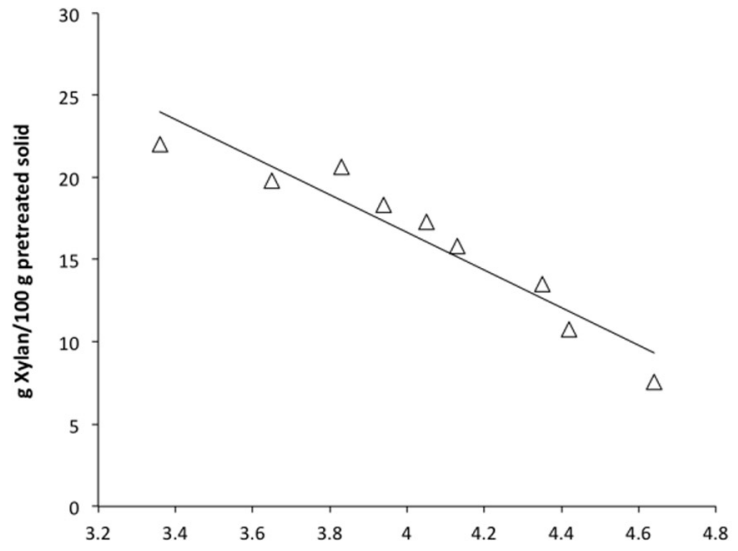

(A)

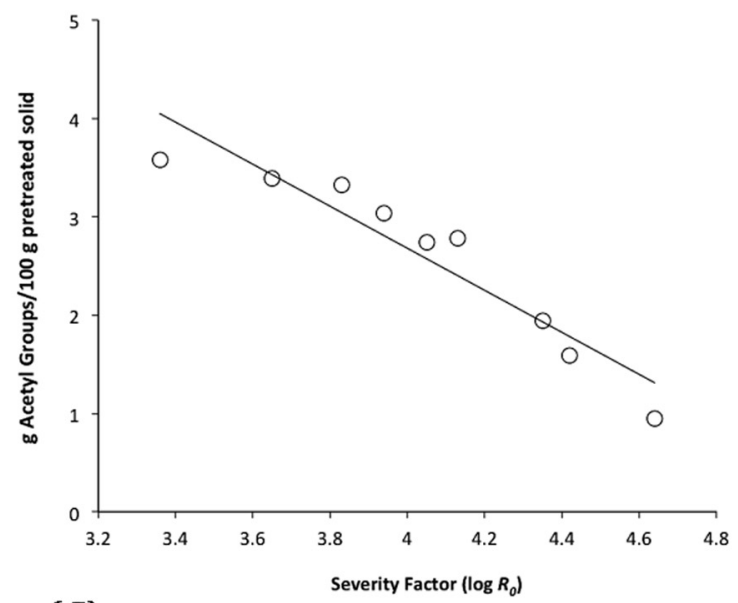

(C)

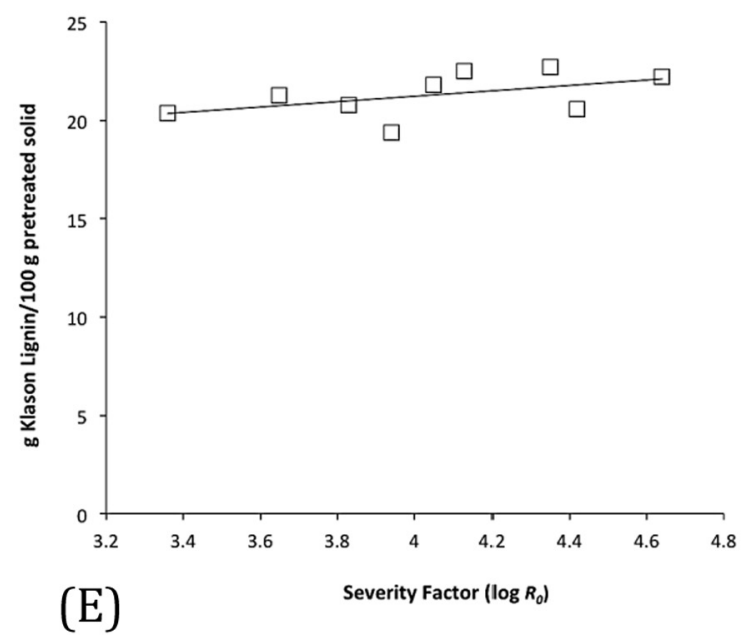

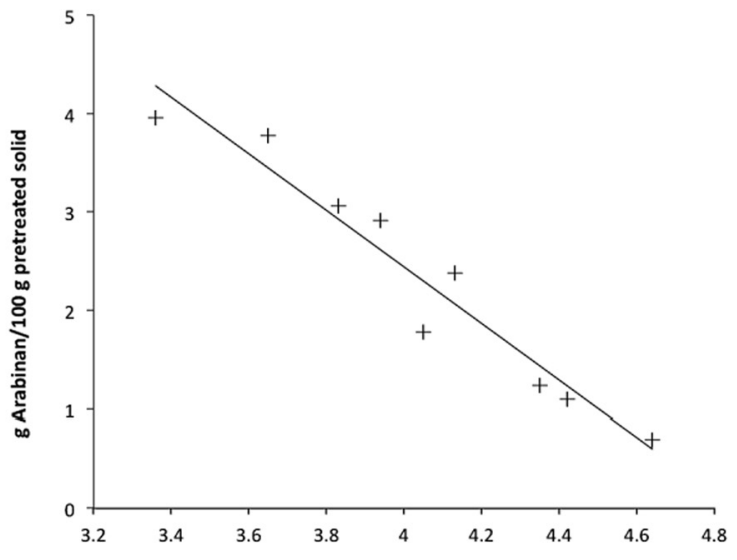

(B)

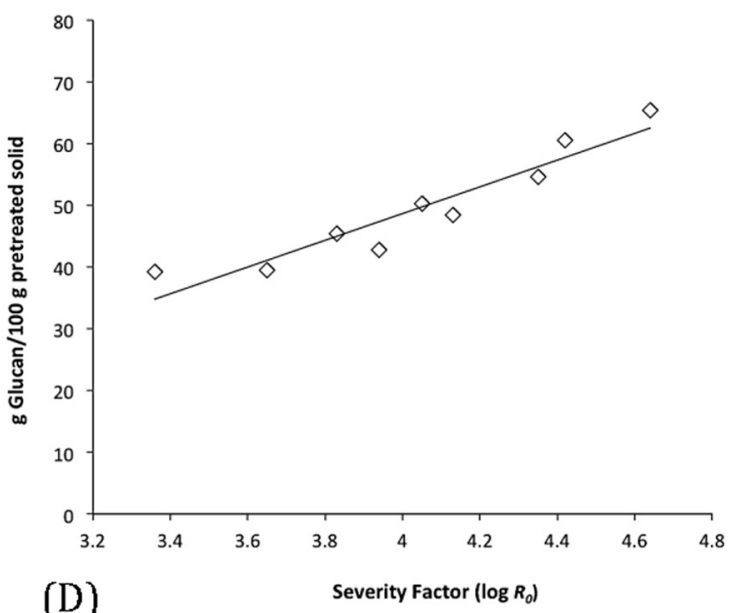

(D) 
The glucose yield (\%) was calculated according to Eq. (3):

Glucose yield $(\%)=\frac{\text { [glucose }]+1.053[\text { cellobiose }]}{1.111 f \text { biomass }]} 100$

where [glucose] is the glucose concentration $(\mathrm{g} / \mathrm{L})$, [cellobiose] is the cellobiose concentration $(\mathrm{g} / \mathrm{L})$, [biomass] is the dry biomass concentration at the beginning of the enzymatic saccharification $(\mathrm{g} / \mathrm{L}), f$ is the cellulose fraction in dry biomass $(\mathrm{g} / \mathrm{g}), 1.111$ is the factor that converts cellulose to equivalent glucose and the factor 1.053 converts cellobiose to equivalent glucose.

\section{9. $D P P H$ free radical scavenging}

The DPPH scavenging activity of lignin was determined according to the slightly modified method of Blois (1958) that is based on its ability to act as free radical scavenger.

Commercial antioxidants like trolox, and butylated hydroxytoluene (BHT) were used as reference. Briefly, $150 \mathrm{mM}$ solution of DPPH was prepared and diluted in ethanol to get an absorbance of 0.700 at $517 \mathrm{~nm}$. A volume of $200 \mu \mathrm{L}$ of this solution was added to $25 \mu \mathrm{L}$ of lignin samples dispersed in $60 \%$ ethanol at different concentrations (0.05-1 $\mathrm{mg} / \mathrm{mL})$. These solutions were incubated in the dark for $30 \mathrm{~min}$ at room temperature. The decrease of the solution absorbance, due to proton donating activity, was measured using a UV-Vis spectrophotometer against a control sample $(200 \mu \mathrm{L}$ of DPPH mixed with $25 \mu \mathrm{L}$ of ethanol).

The percentage of radical scavenging activity (RSA) was calculated using the Eq. (4):

$\operatorname{RSA}(\%)=\left[\frac{\left(A_{\text {control }}-A_{\text {sample }}\right)}{A_{\text {control }}}\right] \times 100$

where $A_{\text {control }}$ is the absorbance of the control sample and $A_{\text {sample }}$ is the absorbance of the lignin sample. The $\mathrm{IC}_{50}$ (half maximal inhibitory concentration) value was calculated as the concentration of the compounds that causes 50\% reduction in the DPPH color (also referred as inhibition). All experiments were carried out in triplicate.

\section{Results and discussion}

\subsection{Chemical composition of untreated and LHW pretreated corncob}

The composition of the feedstock and its transformation during the pretreatment are the main focus in the lignocellulosic biomass conversion process (Liu and Chen 2015). The composition of untreated CC biomass used in this work (as a percentage by dry weight) was: $37.95 \%$ cellulose (measured as glucan), $23.74 \%$ xylan, $4.13 \%$ arabinan, $3.65 \%$ acetyl groups, $19.09 \%$ lignin and $0.77 \%$ ashes. The difference includes non-analyzed components of minor importance for this study, such as extractives or acid-soluble lignin.

The total sugar content was about $65 \%$, being glucan and xylan the main polysaccharides presented. Like other crop-based residues, xylan in CC is analogous to hardwood xylan and consists of a $\beta$-D-(1,4)-linked xylopyranosyl backbone, substituted with arabinose, acetyl groups, and xylose. This chemical composition was similar to some previously reported values in the literature (Garrote et al., 2007; Michelin et al., 2012a; Xie et al., 2014; Michelin and Teixeira 2016). On the other hand, some authors reported corncob presenting $40.38 \%-42.6 \%$ cellulose, $39.04 \%-46 \%$ hemicellulose, and $7.26 \%-7.56 \%$ lignin (Boonsombuti et al., 2013; Boonchuay et al., 2014). These results reflect the difference in corncob biomass itself, which depend on the climate and the agro-technical conditions.

Fig. 1 shows the recovery of xylan, arabinan, acetyl groups, glucan, and Klason lignin (acid-insoluble lignin) as a function of the severity factor after LHW pretreatment. As expected, the fraction of dissolved solids mainly corresponded to hemicellulose solubilization and depolymerization, once LHW mainly affects hemicellulose components; and a decrease in the hemicellulose content of the pretreated CC was observed with the increase of both holding temperature and residence time (Fig. 1A-C). The results also showed that most of the hemicellulose in CC biomass was removed at high pretreatment severity. Within hemicellulose, acetyl groups are the first to be hydrolyzed, followed by arabinan and xylan. This component (acetyl) of the side chains of the xylan backbone facilitates the autohydrolysis effect in LHW (Michelin et al., 2015).

In contrast to hemicellulose components, glucan content increased in the pretreated solids, being the highest glucan content $(65.4 \%)$ obtained at $200{ }^{\circ} \mathrm{C}$ for $50 \mathrm{~min}$, i.e. in the pretreatment of higher severity (Fig. 1D). This behavior is related to the solubilization of hemicellulose components that was higher in the more severe pretreatment conditions, since cellulose suffers little modification in LHW pretreatments. These results are in good agreement with previous reports for similar feedstock, such as rye straw (Gullón et al., 2010), sugarcane bagasse (Vallejos et al., 2015) and corn stover (Liu and Chen, 2015).

Acid-insoluble lignin content in the pretreated solids ranged from $19.4 \%$ to $22.7 \%$, increasing to a higher holding temperature and residence time. However, the solubilization of lignin was relatively low demonstrating that hydrothermal pretreatment does not significantly change lignin structure; the most important effect in the pretreated solids is the re-localization of the lignin (Fig. 1E).

\subsection{Chemical composition of hydrolysates from LHW pretreatment}

LHW pretreatments were carried out under several operational conditions aiming a maximal extraction of xylo-oligosaccharide and a more accessible pretreated biomass. A variety of both non-volatile components, including monosaccharides (xylose, arabinose and glucose) and oligosaccharides (xylo-oligosaccharides - XOS, arabino-oligosaccharides - ArOS, gluco-oligosaccharides - GOS, and acetyl groups linked to oligosaccharides - AcOS), and volatile components, mainly acetic acid, furfural and HMF appeared into the hydrolysates.

Fig. 2 shows the XOS extraction yield and sugar-degradation products (HMF and furfural) recovery, as well as the $\mathrm{pH}$, as a function of the severity factor. XOS were the major components of hydrolysates obtained for all the analyzed conditions. The concentration of XOS increased for higher severity values, and reached a maximum at $\log \left(R_{0}\right)$ of 4.42 (Fig. 2A). The maximal extraction yield of XOS was $93 \mathrm{~g}$ XOS/ $100 \mathrm{~g}$ xylan. For higher values of the pretreatment severity factor, the hydrolytic degradation proceeds, and the XOS of high molecular weight are converted into oligomers of low molecular weight, xylose and furfural in subsequent reactions. Therefore, at $\log \left(R_{0}\right)$ of 4.64 , the extraction yield of XOS decreased, explained by the conversion/degradation of XOS to xylose and subsequently to furfural.

Table 1 presents the concentration of the hydrolysates components $(\mathrm{g} / \mathrm{L})$, i.e. xylose, arabinose, glucose and acetic acid bound in oligomers as well as the free monomers, in all studied conditions. As mentioned previously LHW pretreatment mainly solubilized the xylan into XOS $\left(22.1 \mathrm{~g} / \mathrm{L}\right.$ at $\log \left(R_{0}\right)$ of 4.42 and $16.8 \mathrm{~g} / \mathrm{L}$ at $\log \left(R_{0}\right)$ of 4.64$)$ and small amounts of xylose, which were detected into the hydrolysates $(1.1 \mathrm{~g} / \mathrm{L}$ at $\log \left(R_{0}\right)$ of 4.42 and $2.7 \mathrm{~g} / \mathrm{L}$ at $\log \left(R_{0}\right)$ of 4.64$)$. In the most severe condition, it is clear the high degradation of XOS into xylose and furfural (Fig. 2B).

Regarding the low amounts of glucose (glucose bound to oligomers as well as the free glucose) detected into the hydrolysates, it is important to highlight that this glucose could be derived from hemicellulose or from depolymerized cellulose, indicating in the last case, a limited hydrolysis of the cellulose under the experimental conditions used. In general, GOS concentration increased for higher holding temperatures and residence times, while glucose concentrations decreased. Maximum of $1.4 \mathrm{~g} / \mathrm{L}$ GOS and $0.13 \mathrm{~g} / \mathrm{L}$ glucose at $\log \left(R_{0}\right)$ of 4.64 (Table 1) were detected. HMF concentration also increased with the severity of the pretreatment conditions being the maximal 

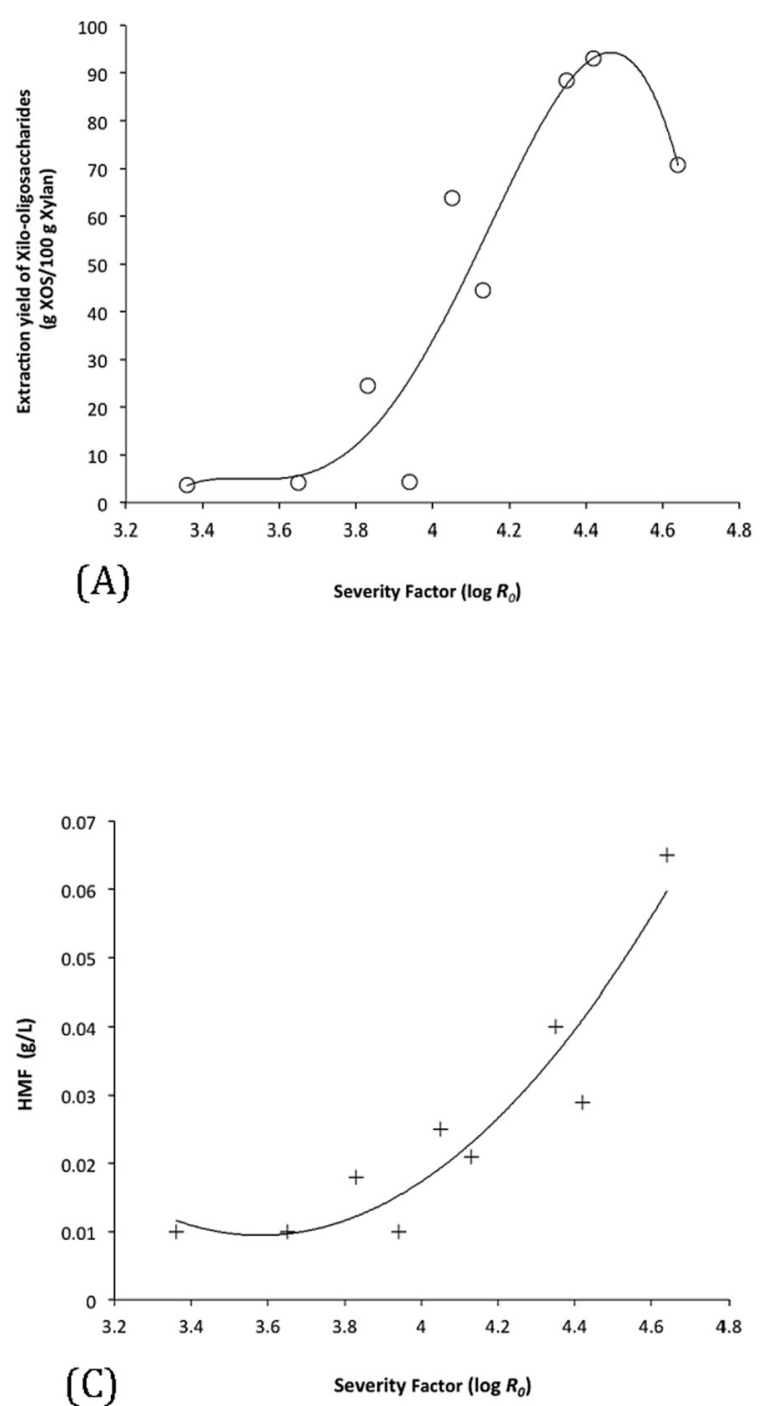

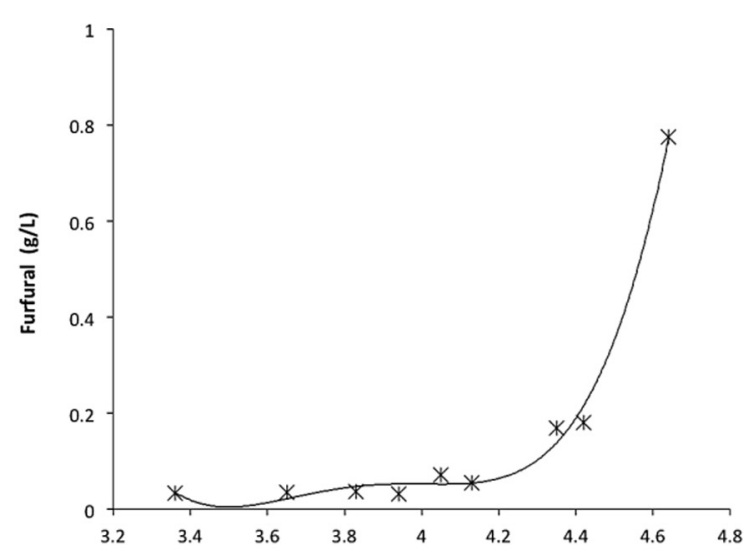

(B) Severity Factor $\left(\log R_{0}\right)$

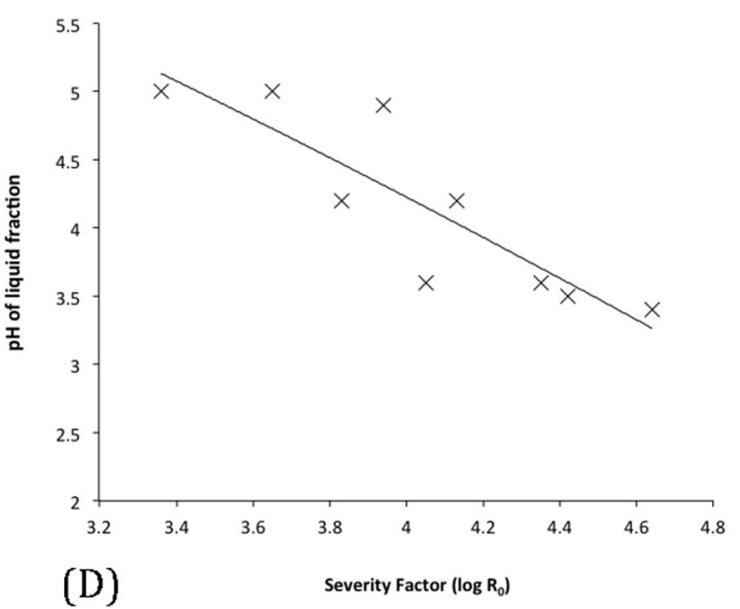

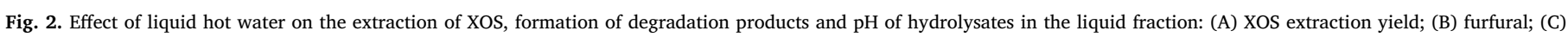
hydroxymethylfurfural (HMF), and (D) $\mathrm{pH}$ of hydrolysates.

concentration obtained of $0.07 \mathrm{~g} / \mathrm{L}$ (Fig. 2C).

It is important to highlight that the achieved furfural and HMF concentrations (maximal of $0.78 \mathrm{~g} / \mathrm{L}$ and $0.07 \mathrm{~g} / \mathrm{L}$ ) is considered quite low compared with other pretreatments, such as dilute acid pretreatment (Wang et al., 2011). The generation of low concentrations of degradation compounds is a characteristic of LHW pretreatment and an advantage regarding to other processes. The formation of degradation compounds (inhibitors) is related to the $\mathrm{pH}$ of the process, and it has been suggested to control the $\mathrm{pH}$ between 4 and 7 to avoid the formation of degradation products, since at this $\mathrm{pH}$ range the hemicellulosic sugars are retained in oligomeric form and monomers formation is minimized (Mosier et al., 2005). In this study the $\mathrm{pH}$ ranged from 3.4 to 5.0 (Fig. 2D), and as expected the higher formation of inhibitor products was observed in the lowest $\mathrm{pH}$.

The low formation of furfural and HMF is important, once concentrations higher than $1 \mathrm{~g} / \mathrm{L} \mathrm{HMF}$ are reported as inhibitory to microbial metabolism (Olsson and Hahn-Hagerdal 1996; Michelin et al., 2012a). Taherzadeh et al. (2000) reported 70\% and 89\% inhibition of

Table 1

Corncob hydrolysates composition obtained from LHW-pretreatment.

\begin{tabular}{|c|c|c|c|c|c|c|c|c|c|}
\hline Operational Conditions $\left(\log R_{O}\right)$ & 3.36 & 3.65 & 3.83 & 3.94 & 4.05 & 4.13 & 4.35 & 4.42 & 4.64 \\
\hline \multicolumn{10}{|l|}{ Oligosaccharides } \\
\hline Xylo-oligosaccharides (g/L) & 0.86 & 0.98 & 5.83 & 1.02 & 15.15 & 10.57 & 20.98 & 22.08 & 16.80 \\
\hline Gluco-oligosaccharides (g/L) & 0.43 & 0.53 & 0.80 & 0.47 & 1.02 & 0.80 & 1.30 & 1.40 & 1.42 \\
\hline Arabino-oligosaccharides (g/L) & 0.04 & 0.06 & 0.58 & 0.06 & 0.95 & 0.65 & 1.28 & 1.10 & 0.52 \\
\hline Acetyl groups-oligosaccharides (g/L) & 0.30 & 0.33 & 0.90 & 0.46 & 1.50 & 1.05 & 2.03 & 2.15 & 1.98 \\
\hline \multicolumn{10}{|l|}{ Monosaccharides } \\
\hline Glucose (g/L) & 0.23 & 0.18 & 0.20 & 0.19 & 0.18 & 0.17 & 0.13 & 0.14 & 0.13 \\
\hline Xylose (g/L) & 0.25 & 0.18 & 0.26 & 0.19 & 0.45 & 0.32 & 0.96 & 1.14 & 2.70 \\
\hline Arabinose (g/L) & 0.01 & 0.05 & 0.56 & 0.06 & 0.92 & 0.77 & 0.92 & 1.02 & 0.85 \\
\hline Acetic acid (g/L) & 0.10 & 0.12 & 0.38 & 0.15 & 0.69 & 0.53 & 0.83 & 0.98 & 1.13 \\
\hline
\end{tabular}


Saccharomyces cerevisiae growth on $4 \mathrm{~g} / \mathrm{L}$ HMF and furfural, respectively, and the presence of both furfural $(2 \mathrm{~g} / \mathrm{L})$ and HMF $(2 \mathrm{~g} / \mathrm{L})$ completely inhibited the growth of this microorganism.

Therefore, the generation of fermentation inhibiting compounds was quite low, which is an advantage for the use of hydrolysates for fermentation purposes as already demonstrated in previous works (Michelin et al., 2012a,b).

\subsection{Production of value-added compounds}

Pretreatment has often been useful for improving the digestibility of lignocellulosic materials and for facilitating access to microbial attack. The hemicellulose removal by LHW is known to disrupt the material structure possibly increasing porosity, and a solid residue with improved enzymatic digestibility is expected. In fact, xylan solubilization is generally considered the main factor to improve $\mathrm{EH}$, although in some cases lignin disruption/removal can also be relevant for further EH. In this context, LHW pretreatment was used to obtain a welladapted substrate for $\mathrm{EH}$ and fermentation. Thus, the solubilized and depolymerized hemicellulose fraction from LHW (hydrolysates) was used as substrate to produce xylanases and the solid fraction enriched in cellulose and also lignin on production of cellulases. On the other hand, solids from two selected conditions of LHW pretreatment $\left(\log \left(R_{0}\right)\right.$ of 4.42 and 4.64) were used as substrate for enzymatic saccharification of cellulose and recovery of fermentable sugars (i.e. glucose) and lignin. A schematic representation of the CC pretreatment by liquid hot water ( $1^{\text {st }}$ processing step) and production of value-added compounds (products) after enzymatic saccharification and fermentation $\left(2^{\text {nd }}\right.$ processing step) is presented on Fig. 3.

\subsubsection{Production of hemicellulases from LHW hydrolysates by Aspergillus} niger

In order to improve the production of biomass-degrading enzymes, the hydrolysates from LHW pretreatment rich in XOS were used as substrate to produce hemicellulases, i.e. xylanases and $\beta$-xylosidases, by A. niger - a recognized producer of xylanolytic enzymes, aiming to obtain a well-adapted substrate for the production of these enzymes. Fig. 4 presents the enzyme production obtained on cultures of $A$. niger.

The production of xylanase (endoxylanase) was higher using hydrolysates obtained at $\log \left(R_{0}\right)$ of 4.13 (Fig. 4A), that contained $10.6 \mathrm{~g} / \mathrm{L}$ XOS (Table 1 ). In this condition was obtained approximately a value of
$10 \mathrm{IU} / \mathrm{mL}$ that was $13.4 \%$ higher than the production for commercial xylan, and $25.3 \%$ higher than untreated CC. These results showed that a well-adapted substrate for the production of this enzyme was achieved, probably due to the more accessible substrate (XOS) for the microbial attack than xylan and untreated CC. Although other fractions presented higher XOS content (Table 1), the highest xylanase production in the fraction of $\log \left(R_{0}\right)$ of 4.13 can be related to the lower amount of inhibitory compounds, such as furfural, HMF and acetic acid, as well as phenolic compounds that could be present (Michelin et al., 2016).

In the case of the $\beta$-xylosidase production, similar enzymatic levels were obtained for all fractions/conditions (Fig. 4B), which ranged from 1.5 to $1.9 \mathrm{IU} / \mathrm{mL}$. The highest production corresponded to $16.7 \%$ and $24.2 \%$ of those from commercial xylan and untreated CC, respectively.

Michelin et al. (2012a) reported an improvement of $15 \%-35 \%$ on enzymatic production in relation to commercial xylan, by using a mixture of untreated CC and hydrolysates from LHW pretreatment at $200{ }^{\circ} \mathrm{C}$ for $30 \mathrm{~min}$. Maximum of $15.2 \mathrm{IU} / \mathrm{mL}$ and $12.1 \mathrm{IU} / \mathrm{mL}$ of xylanase and $0.6 \mathrm{IU} / \mathrm{mL}$ and $1.1 \mathrm{IU} / \mathrm{mL}$ of $\beta$-xylosidase were obtained in cultures of A. terricola and A. ochraceus, respectively. Michelin et al, (2012 b) explored the inclusion of a mixture of $1 \%(w / v)$ wheat bran and $10 \%(\mathrm{v} / \mathrm{v})$ hydrolysates of wheat straw pretreated by LHW at $200{ }^{\circ} \mathrm{C}$ for $15 \mathrm{~min}$ and achieved a xylanase production $20 \%$ higher than commercial xylan and $42 \%$ higher than untreated wheat straw.

Aiming to decrease the cost of enzymes used to hydrolyze biomass, the hydrolysates from the LHW pretreatment of sugarcane bagasse were used in the growth medium of Aspergillus awamori by Paredes et al. (2015). The hydrolysates containing $23.7 \mathrm{~g} / \mathrm{L}$ xylan was diluted and used as carbon source for fungal enzyme production. In a growth medium containing $5 \mathrm{~g} / \mathrm{L}$ xylan, the fungus produced $46 \mathrm{U} / \mathrm{mL}$ of $\mathrm{xy}-$ lanase and $0.24 \mathrm{U} / \mathrm{mL}$ of $\beta$-xylosidase. The xylanase production was higher than that achieved in the present study, but the $\beta$-xylosidase production was lower; this difference can be related to the heterogeneity of the substrate, as well to the potential of each fungus to produce the enzyme.

Anyway, the use of pretreated agro-residues to improve xylanase production is an important approach to add value to these materials as well as to make xylanases production more feasible, since the cost of purified xylan is very high.

\subsubsection{Production of cellulases from LHW solids by Trichoderma reesei}

For cellulases production, the LHW solid fractions (rich in cellulose,

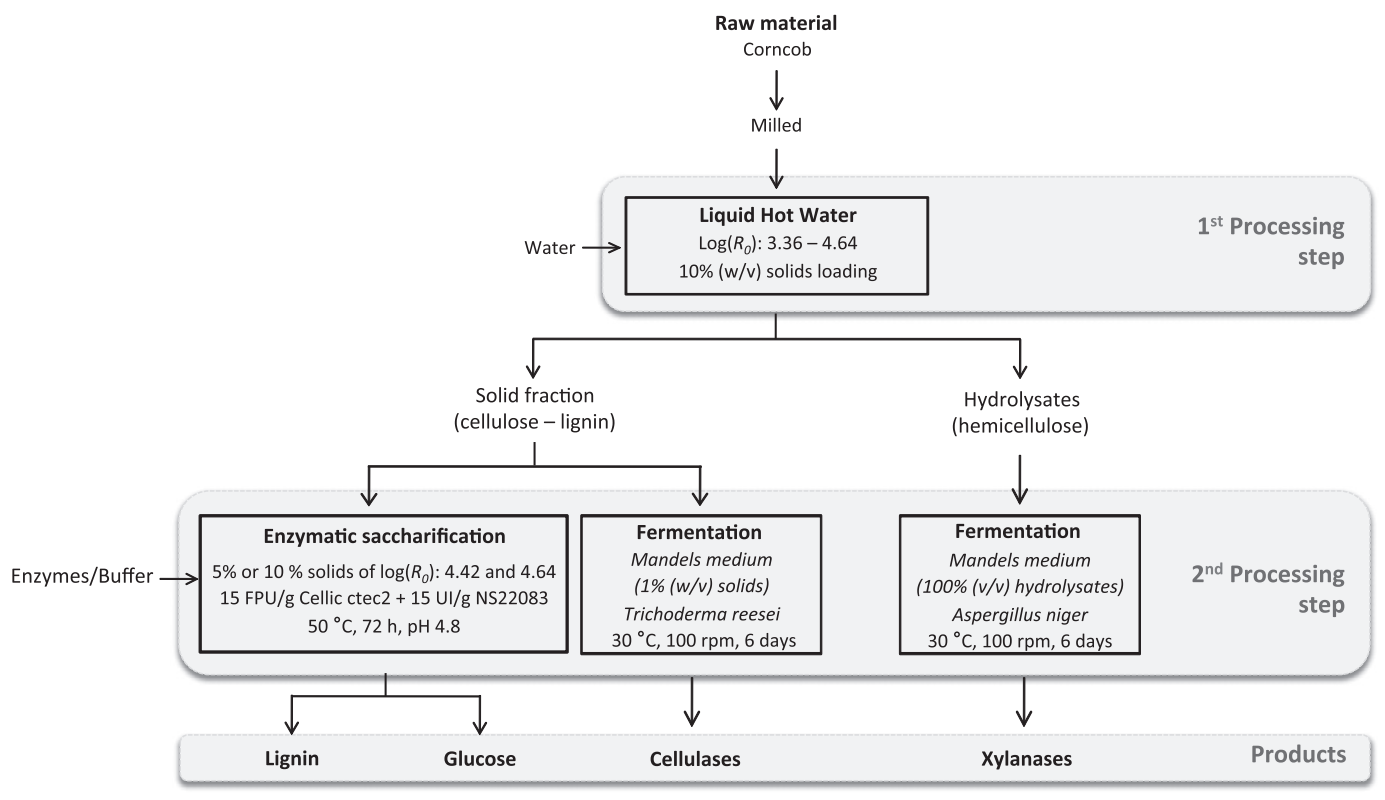

Fig. 3. Schematic representation of the liquid hot water process and enzymatic saccharification for recovery of value-added products. 


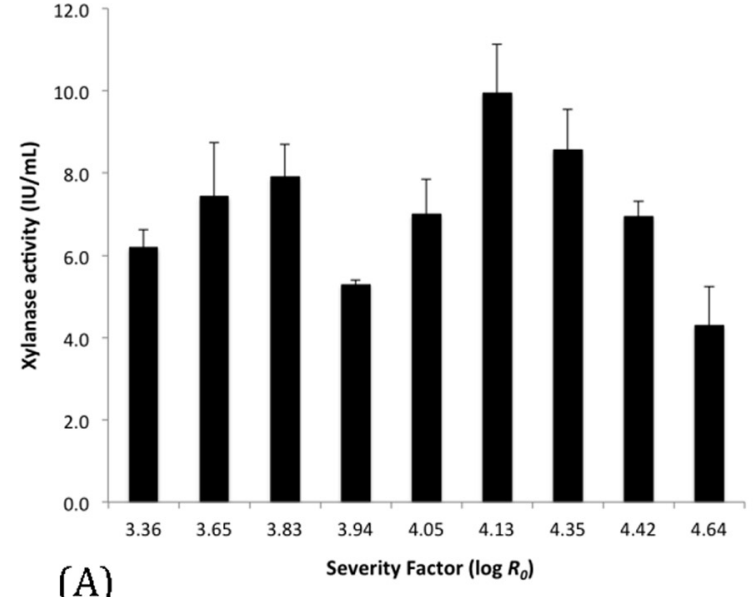

(A)

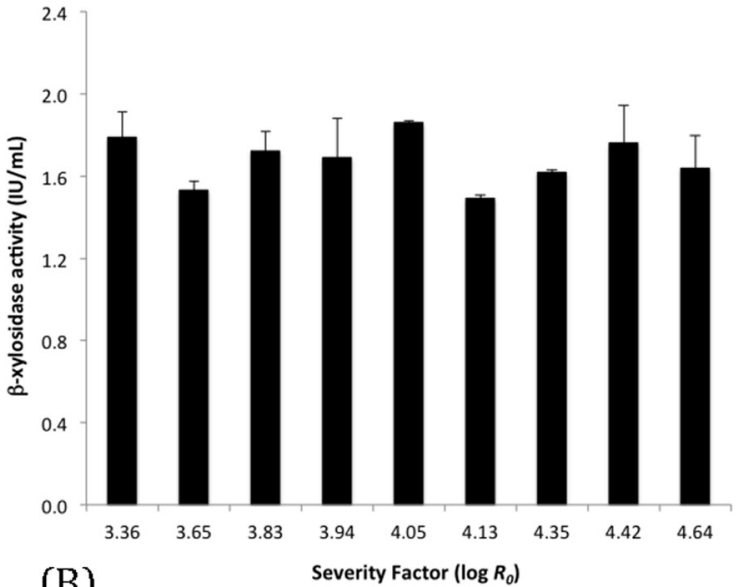

(B)

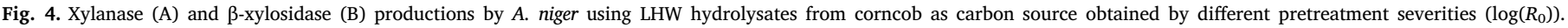
Microorganism was cultivated in Mandels medium at $30^{\circ} \mathrm{C}, 100 \mathrm{rpm}$, for 6 days. Error bars represent standard deviation.

but also lignin) were used as substrate for cultivation of T. reesei, and two activities were evaluated: total cellulase (measured as filter paper activity) and $\beta$-glucosidase.

Regarding to cellulase activity, in general, it was observed an increase in the cellulase production with the increase of the pretreatment severity (Fig. 5A), being the highest cellulase production (measured as filter paper activity) by $T$. reesei verified on extracts using pretreated solids at $\log \left(R_{0}\right)$ of 4.42 and 4.64 (around $3.5 \mathrm{FPU} / \mathrm{mL}$ ). This result can be explained by the high content of cellulose in the solid fraction, once in the highest severities was verified the highest cellulose content $(60 \%-65 \%)$. This production was $20 \%$ higher than untreated CC and only $11.25 \%$ of this production was verified when avicel was used as substrate.

Regarding to $\beta$-glucosidase activity, $3.85 \mathrm{IU} / \mathrm{mL}$ were detected on extracts using pretreated solids at $\log \left(R_{0}\right)$ of 4.42 (Fig. 5B). This enzymatic production was also $20 \%$ higher than untreated CC and corresponded to only $5 \%$ of the enzyme production using avicel as substrate.

Other authors have used pretreated residues on production of biomass-degrading enzymes. Salihu et al. (2015) studied eleven agricultural residues for the cellulolytic enzyme production by $A$. niger and showed the effect of pretreatments (i.e. alkali, acid and oxidative pretreatments) on the improvement of enzyme production. Results showed a maximum production of cellulolytic enzyme on alkali pretreatment of soybean hulls with $6.2 \mathrm{FPU} / \mathrm{g}$ cellulase and $5.7 \mathrm{U} / \mathrm{g}$ of $\beta$-glucosidase.

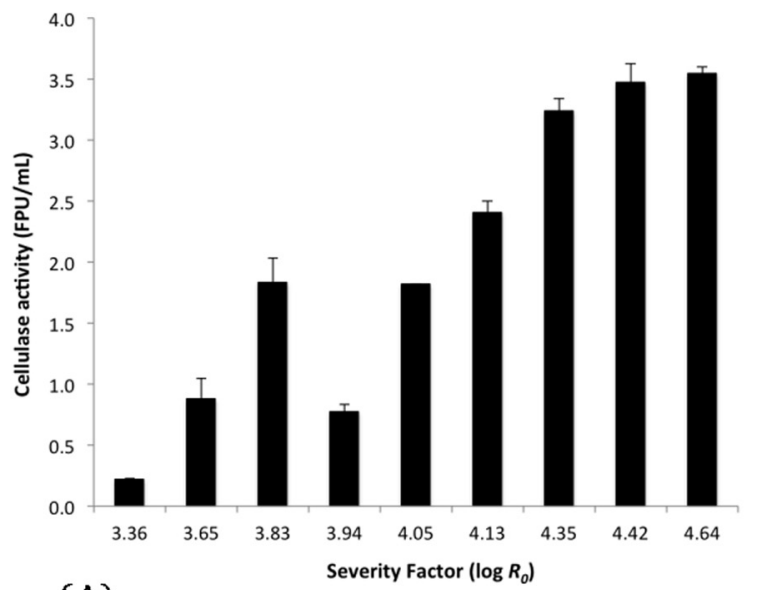

(A)
Pensupa et al. (2013) reported a solid-state fermentation of $A$. niger to produce cellulolytic enzymes by using wheat straw pretreated by different technologies. Around 10 FPU/g cellulase activity was obtained using wheat straw pretreated with dilute acid, and by the addition of yeast extracts and minerals that significantly improved the cellulase production to $24 \mathrm{FPU} / \mathrm{g}$, showing the importance of the optimization of the enzyme production assays.

Zhang et al. (2012) also studied the effect of acid and alkali pretreatments on lignocellulosic materials to produce cellulase/xylanase by $T$. reesei Rut C-30. Three feedstocks (switchgrass, corn stover, and anaerobically digested manure fiber) were evaluated and cultures with alkali pretreated materials showed better results than the acid pretreated samples. Therefore, the type of pretreatment has shown to influence the cellulase production, since pretreatment influences the chemical composition of the recovered material.

Considering the high cost of the enzymes, the use of lignocellulosic residues for enzyme production is an important strategy to produce enzymes at lower costs and to add value to these residues. This is because most of the costs of enzymes production are related to the high costs of the substrates. On the other hand, the high lignocellulose content in some agricultural residues, such as CC, makes them an attractive source for the production of biomass-degrading enzymes by microorganisms. The use of pretreated biomass can further contribute for the improvement of the enzyme production due to a more accessible substrate (less recalcitrant biomass).

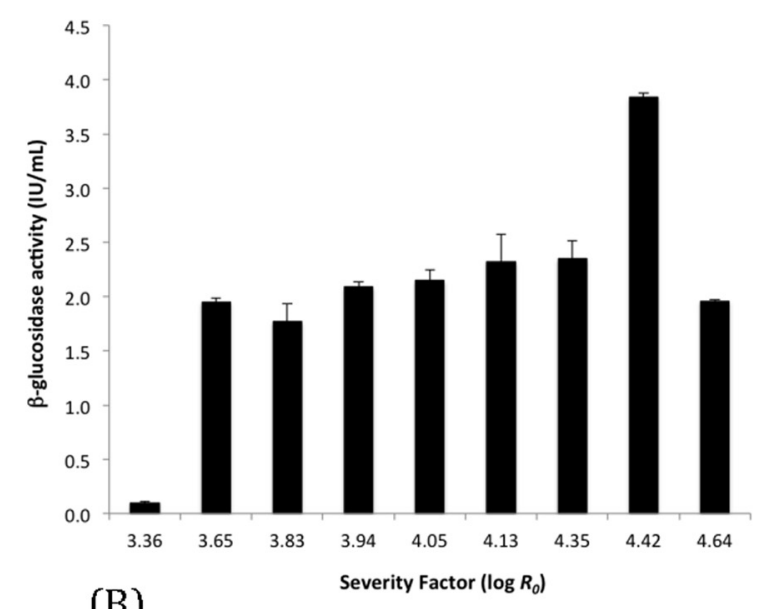

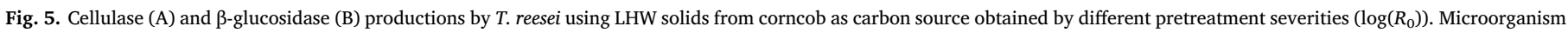
was cultivated in Mandels medium at $30^{\circ} \mathrm{C}, 100 \mathrm{rpm}$, for 6 days. Error bars represent standard deviation. 


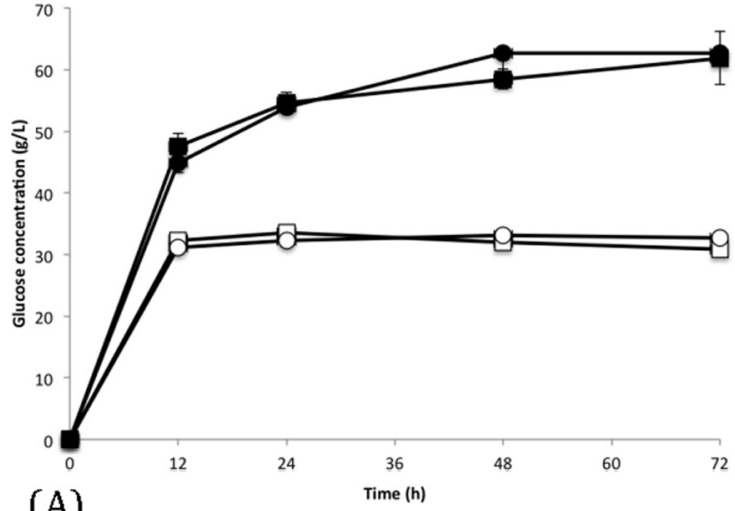

(A)

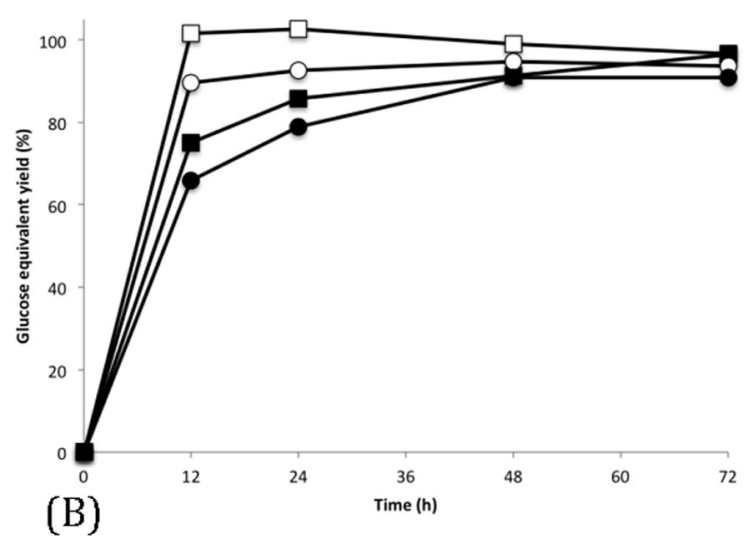

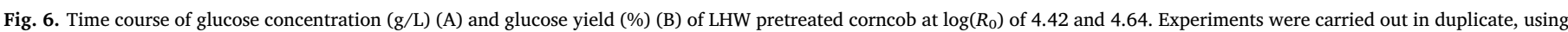

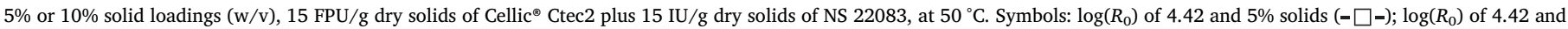
$10 \%$ solids (- - ); $\log \left(R_{0}\right)$ of 4.64 and $5 \%$ solids (- $\left.\bigcirc_{-}\right)$; $\log \left(R_{0}\right)$ of 4.64 and $10 \%$ solids (- - ). Error bars represent standard deviation.

\subsubsection{Production of fermentable sugars}

The enzymatic hydrolysis (EH) step was performed using the pretreated solid fraction from two LHW pretreatment conditions: $\log \left(R_{0}\right)$ of 4.42 and 4.64. A mixture of two commercial enzymes was used in this study, 15 FPU/g dry solids of Cellic ${ }^{\circledR}$ Ctec 2 and 15 IU/g dry solids of NS 22083 , aiming to boost the cellulose conversion to glucose.

Fig. 6 shows the cellulose conversion to glucose (determined by Eq. (3)) of LHW pretreated material. Similar concentration of glucose was recovered from both LHW pretreated solids $\left(\log \left(R_{0}\right)\right.$ of 4.42 and 4.64), and more than $30 \mathrm{~g} / \mathrm{L}$ of glucose was recovered from pretreated solids at $5 \%$ solids loading, while $62 \mathrm{~g} / \mathrm{L}$ of glucose concentration was recovered from pretreated solids at $10 \%$ solids loading (Fig. 6A). From these concentrations, glucose yields higher than $65 \%$ were observed in the first $12 \mathrm{~h}$ with $10 \%$ solids at $\log \left(R_{0}\right)$ of 4.64 ; being the maximal glucose yield (100\%) verified in the first $12 \mathrm{~h}$ with $5 \%$ solids at $\log \left(R_{0}\right)$ of 4.42 (Fig. 6B).

Rodrigues et al. (2015) also achieved a high glucose yield ( $>98 \%$ ) during $96 \mathrm{~h}$ hydrolysis (corresponding to $>65 \mathrm{~g} / \mathrm{L}$ glucose) of steam pretreated wheat straw, using an enzyme loading of $10 \mathrm{FPU} / \mathrm{g}$ cellulose (Cellic ${ }^{\circledR}$ CTec2) and a biomass concentration of $12 \%(\mathrm{w} / \mathrm{v})$ on a dry weight basis. In previous work, Michelin and Teixeira (2016) achieved almost $50 \%$ of glucose yield after $72 \mathrm{~h}$ hydrolysis using $5 \%$ solids and $15 \mathrm{FPU} / \mathrm{g}$ solids, but with CC pretreated at $\log \left(R_{0}\right)$ of 4.13 . Domínguez et al. (2017) also verified that autohydrolyzed solids pretreated at low severities $(<3.99)$ presented a low glucose yield, reaching values $<$ $50 \%$ after $120 \mathrm{~h} \mathrm{EH}$. On the other hand, $100 \%$ of glucose yield (27.5 g/ L) was achieved when Paulownia wood was pretreated at severity of 4.82. In this experiment they used a cellulase to substrate ratio of 20 FPU/g, solids loadings of 4.8\%, and Novozyme 188 and Celluclast $1.5 \mathrm{~L}$ enzymes (Domínguez et al., 2017).

Ruiz et al. (2012) obtained a maximum extent of the enzymatic conversion of cellulose to glucose of $90.9 \%$ at $96 \mathrm{~h}$ and $85 \%$ at $72 \mathrm{~h}$ using LHW pretreated wheat straw as raw material. However, they used $40 \mathrm{FPU} / \mathrm{g}$ cellulose of Celluclast $1.5 \mathrm{~L}$ plus $60 \mathrm{IU} / \mathrm{g}$ Novozyme 188 and $1 \%$ of cellulose concentration. Hongdan et al. (2013) used $2 \%$ of LHW pretreated sugarcane bagasse and $20 \mathrm{FPU} / \mathrm{g}$ substrate and the maximum glucose yield in enzyme hydrolysate was $37.27 \mathrm{~g}$ per $100 \mathrm{~g}$ raw material at $200{ }^{\circ} \mathrm{C}$ for $20 \mathrm{~min}$, representing $90.13 \%$ of glucose in the sugarcane bagasse.

Other examples include Fockink et al. (2015) that studied the cellulose conversion to glucose using $5 \%(\mathrm{w} / \mathrm{v})$ solids and $11.5 \mathrm{FPU} / \mathrm{g}$ dry substrate ( $85 \mathrm{mg} / \mathrm{g}$ dry substrate) of Cellic ${ }^{\oplus}$ Ctec 2 and obtained $<60 \%$ and $<50 \%$ cellulose conversion on alkali pretreated cotton gin dust and alkali pretreated cotton gin waste, respectively, after $72 \mathrm{~h} \mathrm{EH}$.

\subsubsection{Recovery of lignin}

$\mathrm{EH}$ of the LHW pretreated solids resulted in the recovery of four lignin fractions: EHL1 and EHL2 recovered from pretreated solids from LHW at $\log \left(R_{0}\right)$ of 4.42 and $5 \%$ or $10 \%$ solids, respectively; EHL3 and EHL4 recovered from pretreated solids from LHW at $\log \left(R_{0}\right)$ of 4.64 and $5 \%$ or $10 \%$ solids, respectively.

Fig. 7 shows the DPPH scavenging activity of the EHL samples. The DPPH inhibitory effect increased with the increment of lignin concentrations and the results show that all EHL possessed antioxidant activity. The antioxidant activity in terms of percentage of inhibition of the DPPH radicals at $1 \mathrm{mg} / \mathrm{mL}$ achieved values of $69 \%, 71 \%, 70 \%$ and $60 \%$ for the EHL1, EHL2, EHL3 and EHL4, respectively, against 93\% and $96 \%$ inhibition for the commercial antioxidants butylated hydroxytoluene (BHT) and trolox, respectively.

$\mathrm{IC}_{50}$ of the EHL samples were obtained varying lignin concentration from 0.05 to $1 \mathrm{mg} / \mathrm{mL}$. EHL samples had $\mathrm{IC}_{50}$ values ranging from 0.5 to $0.75 \mathrm{mg} / \mathrm{mL}$, while the commercial antioxidants BHT and trolox had values of $0.2 \mathrm{mg} / \mathrm{mL}$ and $0.07 \mathrm{mg} / \mathrm{mL}$, respectively, showing the higher antioxidant potential of the commercial antioxidants. Nevertheless, the EHL2 presented an $\mathrm{IC}_{50}$ value $(0.5 \mathrm{mg} / \mathrm{mL})$ in the same range of BHT. Lu et al. (2012) studied different organosolv pulping methods to extract lignin from Acanthopanax senticosus residue, being the lignin from acetic acid-water method the most effective free radical scavengers, with an $\mathrm{IC}_{50}$ of $0.66 \mathrm{mg} / \mathrm{mL}$; this value is in agreement with the values obtained in this work.

Thus, results showed the potential of using lignin obtained from sequential LHW/EH process as natural antioxidant compound. Further work should be performed exploring their use in cosmetic, pharmaceutical and food industry to ensure their safety and applicability.

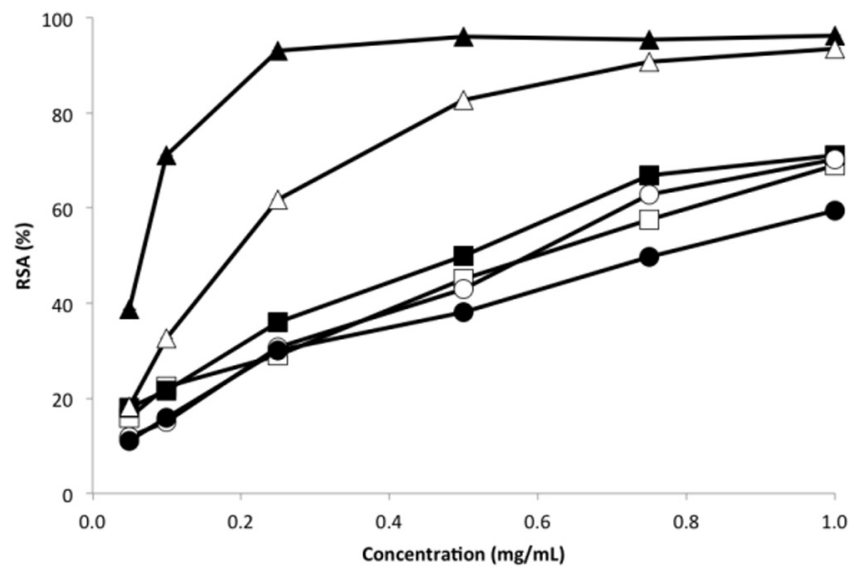

Fig. 7. Scavenging activity of EHL samples compared with commercial antioxidants for DPPH radical. Symbols: EHL1 (- $\square$-); EHL2 (- $\square$-); EHL3 (- O-); EHL4 (- ○ -); trolox (- $\mathbf{\Delta}$ ); BHT (- $\triangle$-). Error bars represent standard deviation. 


\section{Conclusions}

An evaluation of LHW pretreatment on the production of biomassdegrading enzymes, fermentable sugars and recovery of lignin was carried out using corncob. High recovery of hemicellulose-derived compounds (as xylo-oligosaccharides) was obtained into the hydrolysates $\left(22 \mathrm{~g} / \mathrm{L}\right.$ at $\log \left(R_{0}\right)$ of 4.42$)$. On pretreated solids, maximum of $65 \%$ cellulose and $22 \%$ lignin were recovered at $\log \left(R_{0}\right)$ of 4.64 . Hydrolysates and pretreated solids improved the production of xylanases by $A$. niger and cellulases by $T$. reesei, respectively. On the other hand, $\mathrm{EH}$ of the pretreated solids recovered at least $65 \%$ fermentable sugars (achieving 100\% glucose yield with 5\% solid loading) and lignin with antioxidant activity ( $\mathrm{IC}_{50}: 0.5-0.75 \mathrm{mg} / \mathrm{mL}$ ).

\section{Acknowledgements}

Michele Michelin is a recipient of a FCT fellowship (SFRH/BPD/ 100786/2014). This study was supported by the Portuguese Foundation for Science and Technology (FCT) under the scope of the strategic funding of UID/BIO/04469/2013 unit and COMPETE 2020 (POCI-010145-FEDER-006684) and BioTecNorte operation (NORTE-01-0145FEDER-000004) funded by the European Regional Development Fund under the scope of Norte2020 - Programa Operacional Regional do Norte. Héctor Ruiz would like to thank the financial support to the Mexican Science and Technology Council (CONACYT, Mexico) for the Basic Science Project-2015-01 (Ref. 254808) and the Energy Sustainability Fund 2014-05 (CONACYT-SENER), Mexican Centre for Innovation in Bioenergy (Cemie-Bio), and Cluster of Bioalcohols (Ref. 249564). We thank Dr. Nelson Lima from MUM (Micoteca da Universidade do Minho, PT) that gently provided the Trichoderma reesei fungi.

\section{References}

Blois, M.S., 1958. Antioxidant determination by the use of a stable free radical. Nature $181,1199-1200$

Boonchuay, P., Techapun, C., Seesuriyachan, P., Chaiyaso, T., 2014. Production of xylooligosaccharides from corncob using a crude thermostable endo-xylanase from Streptomyces thermovulgaris TISTR1948 and prebiotic properties. Food Sci. Biotechnol. 23 (5), 1515-1523.

Boonsombuti, A., Luengnaruemitchai, A., Wongkasemjit, S., 2013. Enhancement of enzymatic hydrolysis of corncob by microwave-assisted alkali pretreatment and its effect in morphology. Cellulose 20, 1957-1966.

Domínguez, E., Romaní, A., Domingues, L., Garrote, G., 2017. Evaluation of strategies for second generation bioethanol production from fast growing biomass Paulownia within a biorefinery scheme. Appl. Energy 187, 777-789.

EUROSTAT, 2017. Crop statistics. Source: http://appsso.eurostat.ec.europa.eu/nui/show. do?dataset $=$ apro_acs_a\&lang $=$ en.

FAO, 2016. Food Outlook. Source: http://www.fao.org/3/a-I5703E.pdf.

Fockink, D.H., Maceno, M.A.C., Ramos, L.P., 2015. Production of cellulosic ethanol from cotton processing residues after pretreatment with dilute sodium hydroxide and enzymatic hydrolysis. Bioresour. Technol. 187, 91-96.

Garrote, G., Falqué, E., Domínguez, H., Parajó, J.C., 2007. Autohydrolysis of agricultural residues: Study of reaction byproducts. Bioresour. Technol. 98, 1951-1957.

Ghose, T.K., 1987. Measurement of cellulase activities. Pure Appl. Chem. 59, 257-268.

Gullón, B., Yáñez, R., Alonso, J.L., Parajó, J.C., 2010. Production of oligosaccharides and sugars from rye straw: a kinetic approach. Bioresour. Technol. 101, 6676-6684.

Hongdan, Z., Shaohua, X., Shubin, W., 2013. Enhancement of enzymatic saccharification of sugarcane bagasse by liquid hot water pretreatment. Bioresour. Technol. 143, 391-396.
Liu, Z.-H., Chen, H.-Z., 2015. Xylose production from corn stover biomass by steam explosion combined with enzymatic digestibility. Bioresour. Technol. 193, 345-356.

Lu, Q., Liu, W., Yang, L., Zu, Y., Zu, B., Zhu, M., Zhang, Y., Zhang, X., Zhang, R., Sun, Z., Huang, J., Zhang, X., Li, W., 2012. Investigation of the effects of different organosolv pulping methods on antioxidant capacity and extraction efficiency of lignin. Food Chem. 131, 313-317.

Mandels, M., Weber, J., 1969. The production of cellulases. Adv. Chem. Ser. 95, 391-414. Michelin, M., Polizeli, M.L.T.M., Ruzene, D.S., Silva, D.P., Ruiz, H.A., Vicente, A.A., Jorge, J.A., Terenzi, H.F., Teixeira, J.A., 2012a. Production of xylanase and $\beta$-xylosidase from autohydrolysis liquor of corncob using two fungal strains. Bioprocess. Biosyst. Eng. 35, 1185-1192.

Michelin, M., Ximenes, E., Polizeli, M.L.T.M., Ladisch, M.R., 2016. Effect of phenolic compounds from pretreated sugarcane bagasse on cellulolytic and hemicellulolytic activities. Bioresour. Technol. 199, 275-278.

Michelin, M., Teixeira, J.A., 2016. Liquid hot water pretreatment of multi feedstocks and enzymatic hydrolysis of solids obtained thereof. Bioresour. Technol. 216, 862-869.

Michelin, M., Polizeli, M.L.T.M., Ruzene, D.S., Silva, D.P., Vicente, A.A., Jorge, J.A., Terenzi, H.F., Teixeira, J.A., 2012b. Xylanase and $\beta$-xylosidase production by Aspergillus ochraceus: new perspectives for the application of wheat straw autohydrolysis liquor. Appl. Biochem. Biotechnol. 166, 336-347.

Michelin, M., Ruiz, H.A., Silva, D.P., Ruzene, D.S., Teixeira, J.A., Polizeli, M.L.T.M., 2015. Cellulose from lignocellulosic waste. In: Ramawat, K.G., Mérillon, J.-.M. (Eds.), Polysaccharides: Bioactivity and Biotechnology. Springer International Publishing, Switzerland, pp. 475-512.

Miller, G.H., 1959. Use of dinitrosalicylic acid reagent for determination of reducing sugar. Anal. Chem. 31, 426-429.

Mosier, N., Hendrickson, R., Ho, N., Sedlak, M., Ladisch, M.R., 2005. Optimization of pH controlled liquid hot water pretreatment of corn stover. Bioresour. Technol. 96 , 1986-1993.

Olsson, L., Hahn-Hagerdal, B., 1996. Fermentation of lignocellulosic hydrolysates for ethanol production. Enzyme Microb. Technol. 18, 312-331.

Paredes, R.S., de Barros, R.R.O., Inoue, H., Yano, S., Bon, E.P.S., 2015. Production of xylanase, $\alpha$-L-arabinofuranosidase, $\beta$-xylosidase, and $\beta$-glucosidase by Aspergillus awamori using the liquid stream from hot-compressed water treatment of sugarcane bagasse. Biomass Conv. Bioref. 5, 299-307.

Pensupa, N., Jin, M., Kokolski, M., Archer, D.B., Du, C., 2013. A solid state fungal fermentation-based strategy for the hydrolysis of wheat straw. Bioresour. Technol. 149, 261-267.

Rodrigues, A.C., Haven, M.O., Lindedam, J., Felby, C., Gama, M., 2015. Celluclast and Cellic ${ }^{\oplus}$ CTec2: Saccharification/fermentation of wheat straw, solid-liquid partition and potential of enzyme recycling by alkaline washing. Enzyme Microb. Technol. 79-80, 70-77.

Ruiz, H.A., Vicente, A.A., Teixeira, J.A., 2012. Kinetic modeling of enzymatic saccharification using wheat straw pretreated under autohydrolysis and organosolv process. Ind. Crops Prod. 36, 100-107.

Salihu, A., Abbas, O., Sallau, A.B., Alam, M.Z., 2015. Agricultural residues for cellulolytic enzyme production by Aspergillus niger: effects of pretreatment. 3. Biotech 5, $1101-1106$.

Sluiter, A., Hames, B., Ruiz, R., Scarlata, C., Sluiter, J., Templeton, D., Crocker, D., 2008. Determination of structural carbohydrates and lignin in biomass. NREL - LAP. Technical Report NREL/TP-510-42618.

Sweeney, M.D., Xu, F., 2012. Biomass converting enzymes as industrial biocatalysts for fuels and chemicals: recent developments. Catalysts 2, 244-263.

Taherzadeh, M.J., Gustafsson, L., Niklasson, C., Lidén, G., 2000. Physiological effects of 5hydroxymethylfurfural on Saccharomyces cerevisiae. Appl. Microbiol. Biotechnol. 53, 701-708.

Vallejos, M.E., Felissia, F.E., Kruyeniski, J., Area, M.A., 2015. Kinetic study of the extraction of hemicellulosic carbohydrates from sugarcane bagasse by hot water treatment. Ind. Crops Prod. 67, 1-6.

Wang, G.S., Lee, J.-W., Zhu, J.Y., Jeffries, T.W., 2011. Dilute acid pretreatment of corncob for efficient sugar production. Appl. Biochem. Biotechnol. 163, 658-668.

Xie, N., Jiang, N., Zhang, M., Qi, W., Su, R., He, Z., 2014. Effect of different pretreatment methods of corncob on bioethanol production and enzyme recovery. Cellulose Chem. Technol. 48 (3-4), 313-319.

Yang, B., Dai, Z., Ding, S.-Y., Wyman, C.E., 2011. Enzymatic hydrolysis of cellulosic biomass. Biofuels 2 (4), 421-450.

Zhang, L., Liu, Y., Niu, X., Liu, Y., Liao, W., 2012. Effects of acid and alkali treated lig. nocellulosic materials on cellulase/xylanase production by Trichoderma reesei Rut C30 and corresponding enzymatic hydrolysis. Biomass Bioenergy 37, 16-24. 